\title{
Web25: The Road Ahead, 20-21 January 2015
}

\author{
Exploring the Future of Scholarly Communication \& Academic Publishing ${ }^{1}$
}

\author{
Arnoud de Kemp \\ Initiator \& Conference Chairman, Co-Editor-in-Chief 'Information Services \& Use'
}

In 2006 the first APE Conference brought together all European stakeholders in the fierce Open Access debates of those days. A lot has happened since then.

In January 2015 almost 250 participants from 16 countries came to Berlin to discuss the future of scholarly communication and academic publishing.

The reputed APE 2015 Program Committee had put together a very actual and interesting program.

APE 2015 was opened by Barbara Schneider-Kempf, Director General of the Staatsbibliothek zu Berlin and Prof. Dr. Martin Grötschel, Incoming President of the Berlin Brandenburg Academy of Sciences and President of the Zuse Institute (ZIB) in Berlin.

Dr. Celina Ramjoué, Head of Sector, Open Access to Scientific Publications and Data, European Commission in Brussels presented greetings from the new Commissioner Günther Oettinger, Directorate Digital Economy and Society.

From 25 high level presentations we have selected a few articles for publication in this issue. For the complete program see www.ape2015.eu.

The core themes for APE 2015 were: Open Access, Web 25, Big Data, Open Data, Open Web, Open Science, Open Research, the Future of University Presses, US Policies for Public Access to Scholarly Publications and Data, Infringement of Authors' Rights, APC Billing Infrastructure, RightsLink, Peer Review, Structured Knowledge, Semantics, dotcoms, Sharing, Discovery, Defragmentation, Quality and Reproducibility, Computer-Aided Design, Video Publications, Laboratory Experiments, Climate Science, Data Accessibility, the Communication of Scientific Results, Research Assessments, Research Ethics...

The APE Conferences aim at a better understanding of scholarly communication and the role of information in science, education and society. They encourage the debate about the future of value-added scientific publishing, information dissemination and access to scientific results and offer an independent forum for 'open minds'. Participants have enjoyed this very open atmosphere in the Academy of Sciences at the famous Gendarmenmarkt in Berlin. Participants are: academic, educational, scientific, technological, medical, legal and professional publishers, university presses, researchers, authors, editors, librarians, teachers, learned and professional societies and associations, funding agencies, politicians and policy makers, subscription agencies and booksellers, recruiting agencies and technology providers. APE Conferences provide an inventory and show the way ahead in a collaborative effort involving all

${ }^{1}$ APE - Academic Publishing in Europe, the 10th International APE Conference, 20-21 January 2015, Berlin. 
stakeholders. At the same time they are open for a review of new enabling technologies that may cope with new requirements and also look at sustainability given the changes of behaviour. In and between the private and the public sector there is still no complete understanding of the economics of electronic publishing and of the various functions in the value chains. This is an ongoing discussion. Coherent indicators are needed to measure the actual use and value of scientific information as a basis for future funding in the public sector and for investments in the private sector. As always there will be a lot of time for discussions and meetings with friends and colleagues.

APE 2016 will be held on 19-20 January 2016 in the Berlin Brandenburg Academy of Sciences and Humanities.

Motto: The Digital Agenda: The Road Ahead for Scholarly Communication www.ape2016.eu 